\title{
The Effect of Preconceived Notions and the Lack of Fundamen- tal Skills while Taking General Chemistry
}

\author{
Malinda Wilson Gilmore ${ }^{\text {', }}$ Dwaynia Wilkerson², and Razi Hassan'
}

${ }^{1}$ Department of Physics, Chemistry and Mathematics, ${ }^{2}$ Department of English and Foreign Languages, Alabama Agricultural and Mechanical University, 4900 Meridian Street, Normal, Al 35762, USA

Received: June 12, 2012 / Accepted: July 5, 2012

\begin{abstract}
Science, Technology, Engineering and Mathematics (STEM) are vital areas of national interest. However, there has been a gradual decline in the number of Bachelor of Science (BS) degrees issued in STEM based disciplines from United States' colleges and universities. Research indicates too few students are equipped with the mathematical and analytical skills necessary to be successful in college level mathematics and science courses. Data indicates that millions of people are discouraged from studying mathematics and science because of false assumptions about who has the ability to master these subjects. It has been shown that in General Chemistry courses some students perform exceptionally well, but a large number of students avoid and/or have a fear of General Chemistry, which results in a high drop/failure/ withdrawal (DFW) rate. This is coupled with the fact that they enter college ill-prepared in mathematics and lacking analytical and verbal reasoning/critical thinking skills. This initial negative attitude and deficiency results in a frustrating experience in General Chemistry. It is for these reasons that a study was performed to address the overall goal of determining the attitudes and identifying the foundational levels of the students from Alabama Agricultural and Mechanical University (AAMU), a Historically Black College and University (HBCU), currently enrolled in General Chemistry and attempt to determine the effect on their overall success in General Chemistry. Subsequently, it was determined that a large percentage of students believe that attitude determines their overall success, but most lack self-confidence. In addition, some appeared college ready with respect to their mathematical skills, but, they were lacking in verbal reasoning/critical thinking skills. As a result of a negative attitude and a lack of foundational skills, their grades reflected such negativity and
\end{abstract}

*Corresponding Author: malinda.gilmore@aamu.edu over $50 \%$ of the students earned a grade of "C" or below. These studies revealed supportive evidence as to why there might be a decline in the number of BS graduates in STEM. Keywords: Chemical Education, General Chemistry, STEM.

Abbreviations: STEM - Science, Technology, Engineering, and Mathematics; BS - Bachelor of Science, DFW - drop/failure/ withdrawal, AAMU - Alabama Agricultural and Mechanical University, and $\mathrm{HBCU}$ - Historical Black College and University.

\section{Introduction}

STEM is a vital area of national interest. Recently, there has been a gradual decline in the number of Bachelor of Science (BS) graduates from United States' higher education institutions in the STEM fields (American Association of State Colleges and Universities, 2005). The National Science Foundation firmly believes that to ensure the long-term prosperity of our nation, we must renew our collective commitment to excellence in education and the development of scientific talent (National Science Foundation, 2010). Accordingly, General Chemistry is a foundational course for most STEM disciplines. This course is a requirement for many biology, chemistry, physics, applied science, engineering and technology majors. General Chemistry is mathematics based and requires a solid sense of verbal reasoning and critical thinking skills. In addition to those necessary skills, studies have shown that a student's overall success and retention in General Chemistry is also dependent upon their attitude before taking the course (Lewis, 2009) (California State University).

Current research indicates too few students are prepared with the mathematical and analytical skills necessary to be suc- 
cessful in college level mathematics and science courses (Conley, 2011) (National Science Foundation, 2006). Additional research strongly suggests that mathematics, in particular, is the crucial filter determining access to many prestigious, respected and lucrative STEM careers (Drew, 2011). Generally, students may have limited success in STEM based areas, but more specifically, in the United States, female students, impoverished students and students of color lack the essential skills in mathematics, analytical and verbal reasoning/critical thinking (Bayer Corporation 2010). The determining factors for those sets of students are most commonly wealth and power in our society and economy (Drew, 2011). Data indicates that millions of people are erroneously discouraged from studying mathematics and science because of false assumptions about who has the ability to master these subjects (Drew, 2011). These assumptions become self-fulfilling expectations which ultimately undermine the self-concept of female students, impoverished students and students of color (Drew, 2011).

Alabama Agricultural and Mechanical University (AAMU) is a Historically Black College and University and a Land-Grant Institution where many of its students are traditionally mostly female $(55 \%)$, or first-generation college students $(32 \%)$, or students of color (>95\%) (AAMU). The STEM disciplines at AAMU are housed in the College of Engineering, Technology and Physical Sciences and the College of Agricultural, Life and Natural Sciences. In the Fall 2011, the total enrollment was 5,095, consisting of 4,285 undergraduate. Of these 4,285 undergraduate students, $36 \%$ are in the STEM disciplines (AAMU).

It has been shown that in General Chemistry courses throughout the United States, some students perform exceptionally well, but a large number of students avoid and/or have a fear of General Chemistry which results in a high drop/failure/withdrawal (DFW) rate (California State University). Students typically avoid and are fearful of General Chemistry due to preconceived notions (California State University). This is coupled with the fact that they enter college ill-prepared in mathematics and lacking analytical and verbal reasoning/critical thinking skills. This initial negative attitude and deficiency results in a frustrating experience in General Chemistry. Students who are frustrated with their experience in General Chemistry are more likely not to build enthusiasm for the content and the application of the sciences or other STEM disciplines. They are also less willing to consider majoring or pursuing a career in the STEM disciplines. It is for these reasons that a study was performed to address the overall goal of determining attitudes and identifying the foundational levels of the students from AAMU currently enrolled in General Chemistry and attempt to determine the effect on their overall success in General Chemistry. The information and data collected from the study should allow for curriculum modification and pedagogical enhancements that provide a better experience for students in General Chemistry. Ultimately, our long-term outcome will be heightened awareness regarding student capabilities and expectations so that any student's General Chemistry experience is less frustrating and more beneficial.

\section{Materials and Methods}

\section{General Chemistry Course}

General Chemistry 101 and 102 are general education / introductory chemistry courses. This course teaches students the fundamental laws of matter that governs physical and chemical changes (i.e., atomic and molecular theories, atomic structure, periodic functions, classification of the elements, solutions and electrolytes, etc.). The student enrollment in these courses include freshman through seniors majoring in various STEM disciplines (i.e., chemistry, physics, biology, engineering, etc.). These particular courses are taught by one or more of AAMU's 8 chemistry faculty members whose background include Agricultural and Environmental Chemistry, Organic Chemistry, Plant and Soil Science, Theoretical Chemistry, Inorganic Chemistry, Biochemistry and Physical Chemistry. The class meets three times a week for 50 minutes during any semester. Students are given homework assignments, quizzes, and exams throughout these courses.

\section{Students}

The student participants in this study were enrolled at AAMU. Majors studied included: chemistry, biology, physics, applied science, engineering and technology. The students were enrolled in either General Chemistry 101 or 102. A total of 60 male and female students who were enrolled in Dr. Malinda Gilmore's and Dr. Razi Hassan's class sections were recruited and participated.

\section{Survey/Diagnostic Examination}

A survey and diagnostic examination were given to students enrolled in either General Chemistry 101 or 102. The survey included 8 questions regarding attitude about General Chemistry.

The questions that were posed in the survey were:

1. Is having a positive attitude about taking General Chemistry important for overall success?

2. How confident are you that a grade of B or higher will be arned in General Chemistry?

3. Are you afraid of taking General Chemistry?

4. Do you think General Chemistry is important for your degree choice?

5. How important is mathematics as a foundation for overall success in General Chemistry?

6. How important do you find verbal reasoning/critical thinking to be for General Chemistry?

7. In what level of math are you currently enrolled?

8. Did you take high school chemistry?

The diagnostic exam included sections covering fundamental mathematical skills, vocabulary skills and verbal reasoning/ critical thinking skills. There were 10 mathematical questions, 6 vocabulary questions and 2 verbal reasoning/critical thinking questions. 


\section{Data Analysis}

The survey questions were analyzed separately. Each section of the diagnostic exam was graded separately. Data was graphed using Microsoft Excel.

\section{Results and Discussion}

\section{Students Attitude Towards General Chemistry}

Self-concept is defined here as an evaluation one makes regarding one's own ability and performance in a subject area (Lewis, 2009). In a study performed by Lewis in 2009, 600 students participated and shared their self-concept about chemistry (Lewis, 2009). That data revealed that $18.7 \%$ had a low chemistry self-concept compared with $22.8 \%$ who had a high chemistry self-concept (Lewis, 2009). Students with a high chemistry self-concept scored $5 \%$ higher than predicted on an American Chemical Society (ACS) standardized exam and students with the low self-concept scored $1.76 \%$ lower than their predicted scores (Lewis, 2009).

Students at AAMU who were enrolled in General Chemistry 101 or 102 participated in a survey to determine their attitudes towards General Chemistry. A total of $90 \%$ of students believed that having a positive attitude upon taking General Chemistry is very or extremely important for overall success (Figure la). Only $70 \%$ percent of students were very or extremely confident that they would earn a grade of B or higher in General Chemistry (Figure 1b). Students believed that a positive attitude was important for overall success in General Chemistry; however, their confidence level and attitude towards their performance in General Chemistry decreased by 10\%. Based on the results of the survey, it appears that $50 \%$ percent of the students were not afraid of taking General Chemistry. Thirty percent (30\%) of the students surveyed had a little reservation (Figure 1c). It is important to note the attitude of the students who participated in this survey. Students believe that attitude determines their overall success but those same students lack self- confidence within. The final grades for the General Chemistry 101 and 102 (Figure 2) reveals the possibility that lacking self-confidence may have played a role in the overall success of the students in the courses. In the General Chemistry 101 and 102 courses, $53.33 \%$ of students' final grade was a "C" or below.

General Chemistry is a requirement for biology, chemistry, physics, applied science, engineering and technology majors at $A A M U$ and $42 \%$ of students surveyed believe that General Chemistry is extremely important for their degree choice. $27 \%$ of students felt that it was only a little important (Figure 1d). This perception is of great concern because an individual's attitude typically determines their overall performance. If more students realized the importance of General Chemistry with respect to their specific disciplines, then the overall performance, which is depicted by the final grades earned (Figure 2) would have been better.

Over $80 \%$ of students believe that mathematics is very or extremely important as a foundation for overall success in General Chemistry (Figure 1e). It is important to note that $51 \%$ of students are currently at the Calculus (MTH 125) or above levels (ADV MTH) of mathematics (Figure 1f). At AAMU, $86 \%$ of students find that verbal reasoning/critical thinking skills are very $(33 \%)$ or extremely $(53 \%)$ important for General Chemistry (Figure 1g). $83 \%$ of the students have taken high school chemistry before (Figure 1h). This information is important because mathematics, verbal reasoning/critical thinking skills, and previous exposure to General Chemistry play a significant role in one's performance and overall success in General Chemistry. Previous studies have shown that ACT/SAT mathematics scores correlate strongly with success in chemistry (ACT, 2006). Donovan and Wheland, in 2009, showed that $37 \%$ of their group studies with ACT mathematics scores of 17 succeeded in General Chemistry, whereas $75 \%$ of the group with ACT mathematics scores of 26 succeeded in General Chemistry (Donovan, 2009). It is important to note that here at $A A M U$, the requirements for admission is an 18 on the ACT (AAMU). The average ACT score of our students admitted here at AAMU is 17.4 (AAMU).

Attitude is important. Students can be taught General Chemistry, including equations and theories, and be provided with viable examples, but if their attitudes are negative before taking General Chemistry and they don't believe that it is important for their overall success in their own specific disciplines, they will not perform to the level that is necessary to succeed.

\section{Students and their Mathematical Background}

Mathematics knowledge and skills are essential for overall success in STEM disciplines, specifically, chemistry (i.e., General Chemistry) (PCAST, 2012). Students lack specific mathematics and analytical skills such as the ability to translate word problems in General Chemistry into practical mathematics or lack the ability to perform multi-step mathematics manipulations (Conley, 2011).

The ACT plays as an indicator of success for students in the STEM disciplines/careers. ACT's Educational Planning and Assessment System (EPAS) found in 2005 that fewer than half $(41 \%)$ of ACT tested high school graduates achieved or exceeded the ACT College Readiness Benchmark in Math (ACT, 2006). The average ACT score for students at AAMU is currently 17.4 (AAMU). These results, along with the previous data, prove that there is a significant problem with the foundational mathematical knowledge of AAMU students prior to entering college General Chemistry or any other science or mathematics course.

Students at AAMU who were currently enrolled in General Chemistry 101 or 102 participated in a diagnostic exam for mathematics/analytical skills. The diagnostic exam included 12 questions involving basic addition and subtraction, algebra, conversions, etc. $75 \%$ of students performed at a level of " $\mathrm{C}$ " $(70-79 \%)$ or better on the mathematics / analytical diagnostic exam (Figure 3). Out of the $75 \%$ of students that performed at a level of "C" or above, $30 \%$ of those students scored a " $\mathrm{C}$ ". $25 \%$ of the students performed lower than "C" (<69\%) (Figure $3)$. Less than half of the students $(45 \%)$ scored a "B" or above. It is important to note that less than half of the students scored $a$ " $B$ " or above and assuming that mathematics knowledge and skills are essential for overall success in STEM disciplines, specifi- 

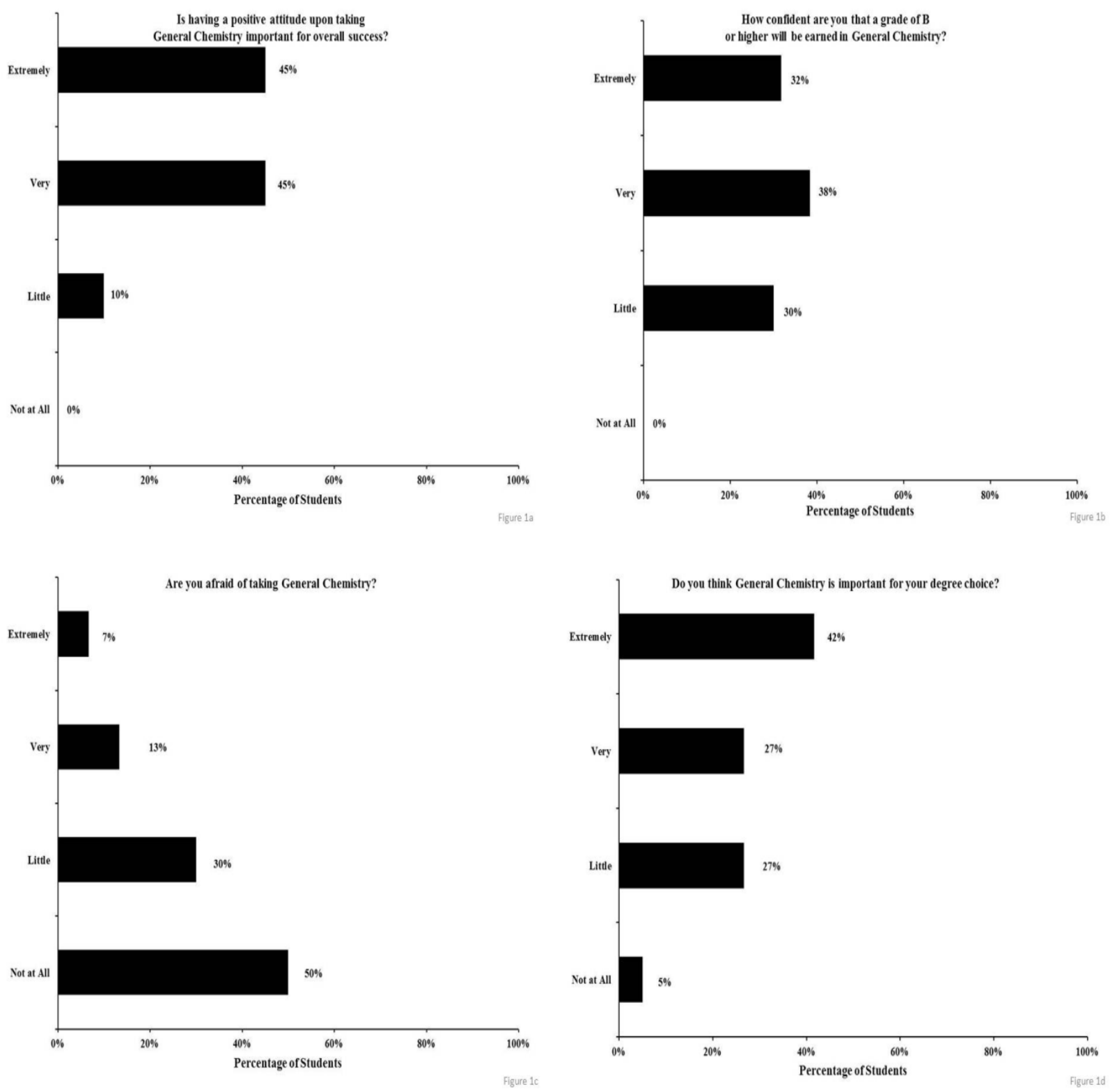

Figure 1. Results of the survey given to students at AAMU enrolled in General Chemistry 101 and 102. a) Is having a positive attitude about taking General Chemistry important for overall success?, b) How confident are you that a grade of B or higher will be earned in General Chemistry?, c) Are you afraid of taking General Chemistry?, d) Do you think General Chemistry is important for your degree choice?, e) How important is mathematics as a foundation for overall success in General Chemistry?, f) How important do you find verbal reasoning/critical thinking to be for General Chemistry?, g) In what level of math are you currently enrolled? and h) Did you take high school chemistry?

cally, Chemistry (i.e., General Chemistry), one can assume based on the diagnostic exam given in mathematics less than half of the students will score a "B" or above in General Chemistry. In comparison with the final grades earned in General Chemistry 101 and 102 (Figure 2) this was proven correct where only $45 \%$ of students earned a "B" or above. Overall, the data shows that students at AAMU are arriving college ready in the area of mathematics.

\section{Students and their Verbal Reasoning/Critical Thinking Skills}

Students entering college chemistry courses typically have received little instruction or encouragement to practice verbal reasoning and/or critical thinking skills. Verbal reasoning is defined as the understanding and reasoning using concepts framed in words (Burton, 2009). It aims at evaluating the ability to think constructively, rather than at simple fluency or vocabulary recognition (Burton, 2009). Critical thinking skills allow an individual to more effectively explore the information that one 

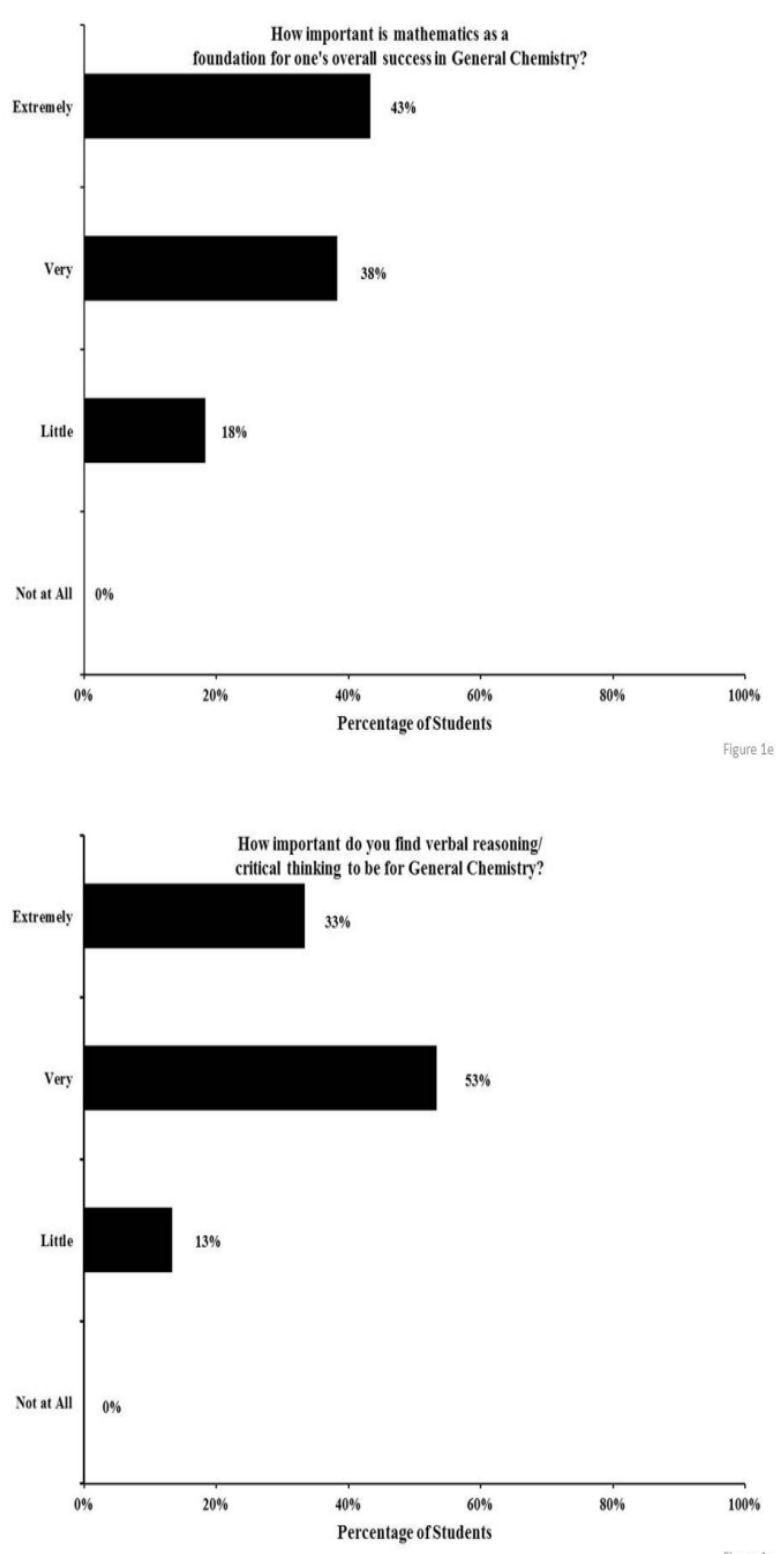

Figure 1. Continued.

acquires through learning and apply this information to a particular subject Burton, 2009). Additionally, critical thinking skills call for effective communication and problem-solving, and require constant analyzing, reasoning and evaluating, especially in the area of General Chemistry.

The studies performed at AAMU to determine the level of verbal reasoning and critical thinking skills of students taking General Chemistry 101 and 102 revealed some very interesting results. The average ACT score for students at AAMU in the area of reading is 17.4 (AAMU). The students used in this assessment were given two different diagnostic exams in this area, one assessing vocabulary and the other assessing abstract reasoning. With respect to vocabulary, the data revealed that $62 \%$ of students scored a "C" or below (Figure 4). Only 38\% of the students scored a "B" or above (Figure 4). This data is disturb-
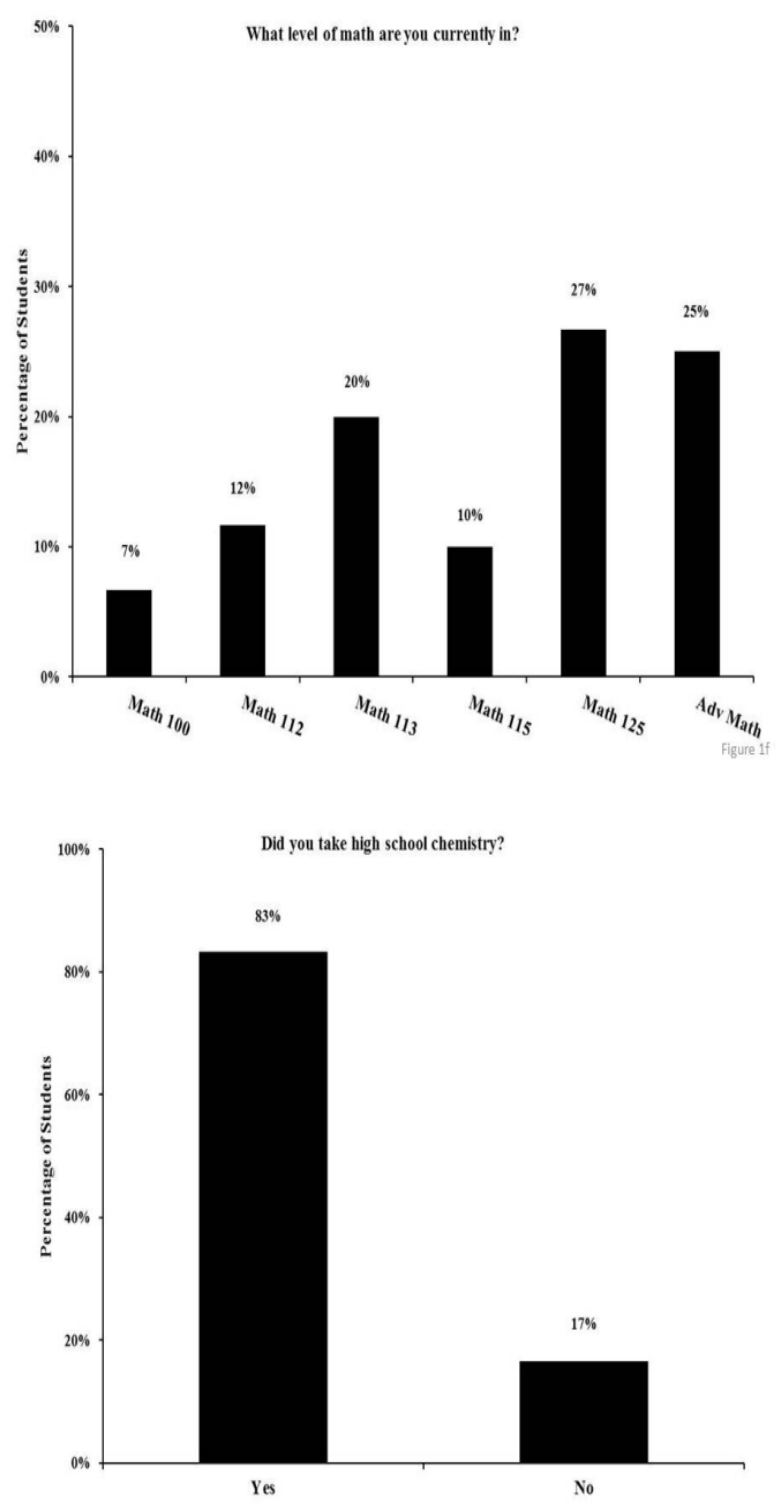

ing because a student must be able to understand and interpret what the question is asking in order to answer the question correctly or perform well in the course or specific discipline.

The students were provided one word problem with two answer choices with respect to assessing their abstract reasoning. The data is shown in Figure 5. 50\% of the students scored a 0 ; $32 \%$ of the students scored a 50 ; and $18 \%$ of students scored a 100 . The data reveals that $82 \%$ of the students did not pass this part of the diagnostic exam for verbal reasoning/critical thinking. Students unable to understand vocabulary and utilize abstract reasoning are already entering General Chemistry, and any other science course or STEM specific course, at a disadvantage. Students struggle in General Chemistry in their ability to apply previous knowledge or new information to conceptual word problems (Pfeiffer, 1998). Previous knowledge includes 


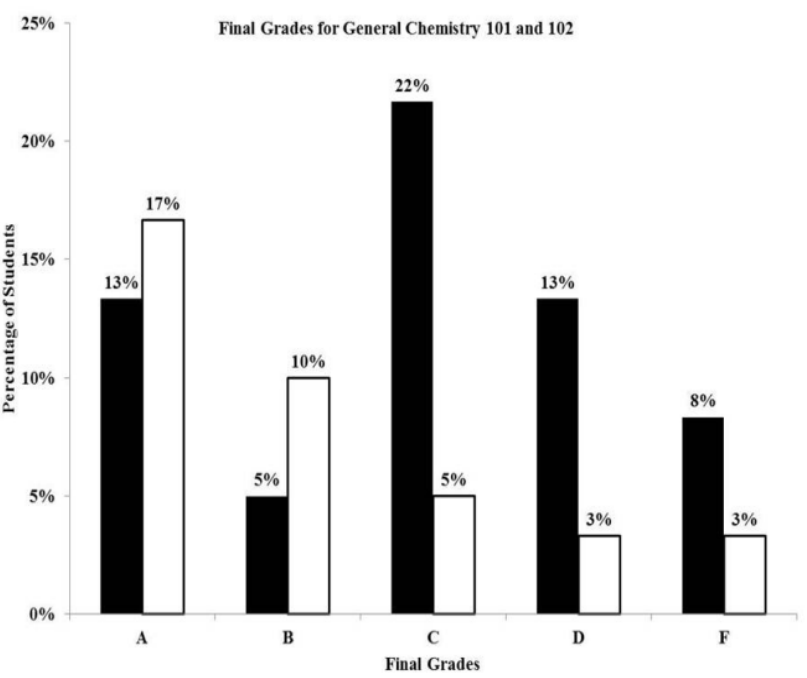

Figure 2. Final Grades of students at AAMU enrolled in General Chemistry 101 and 102 who participated in the survey.

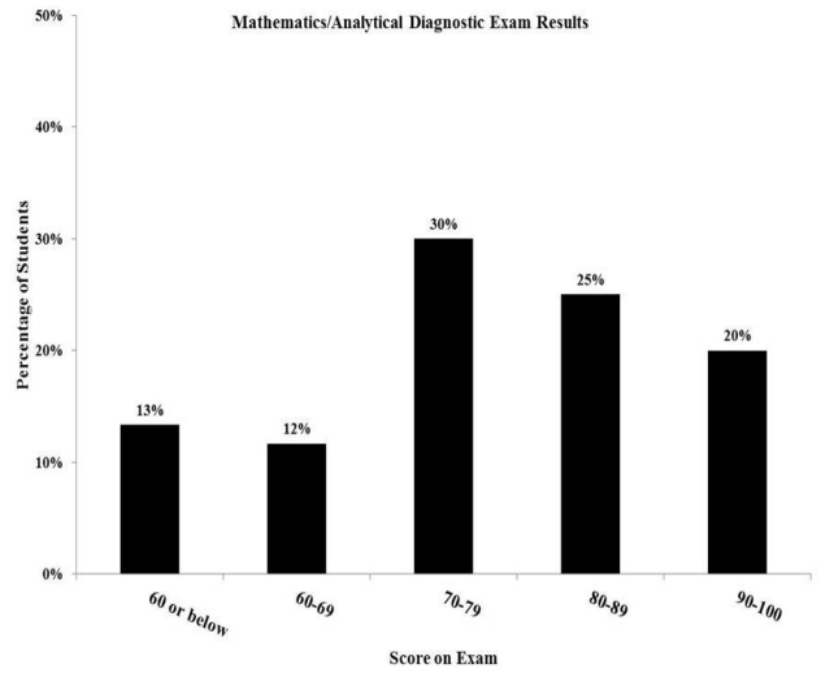

Figure 3. Results of the mathematics/analytical skills diagnostic exam given to students at AAMU enrolled in General Chemistry 101 and 102.

various vocabulary and true understanding of theories and concepts. A broad vocabulary and enhanced abstract reasoning skills allows one to excel in verbal reasoning/critical thinking. A well-cultivated critical thinker possesses the following (Paul, 2008):

- Raises vital questions and problems, formulating them clearly and precisely

- Gathers and assesses relevant information, using abstract ideas to interpret it effectively

- Comes to well-reasoned conclusions and solutions, testing them against relevant criteria and standards

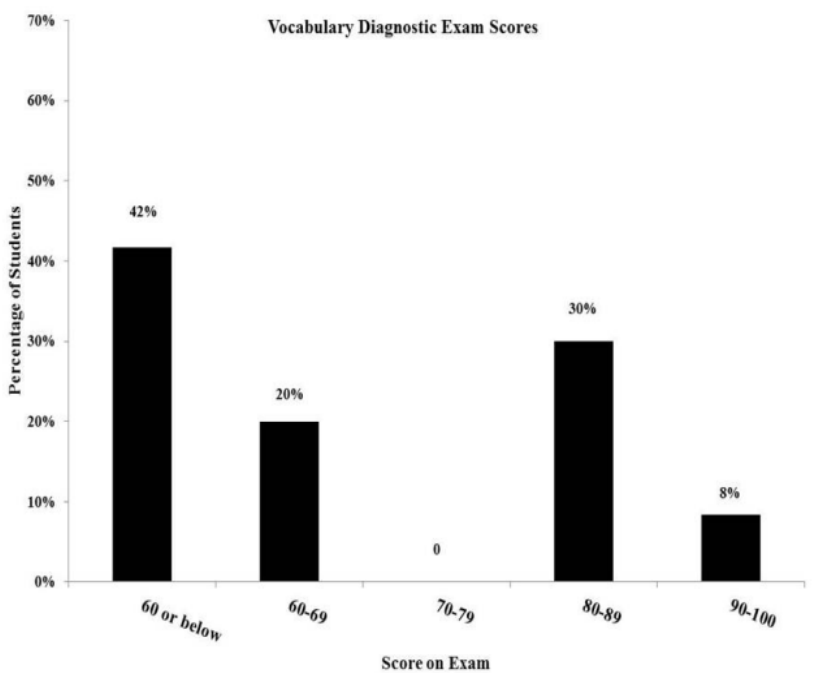

Figure 4. Results of the verbal reasoning / critical thinking diagnostic exam (vocabulary) given to students at AAMU enrolled in General Chemistry 101 and 102

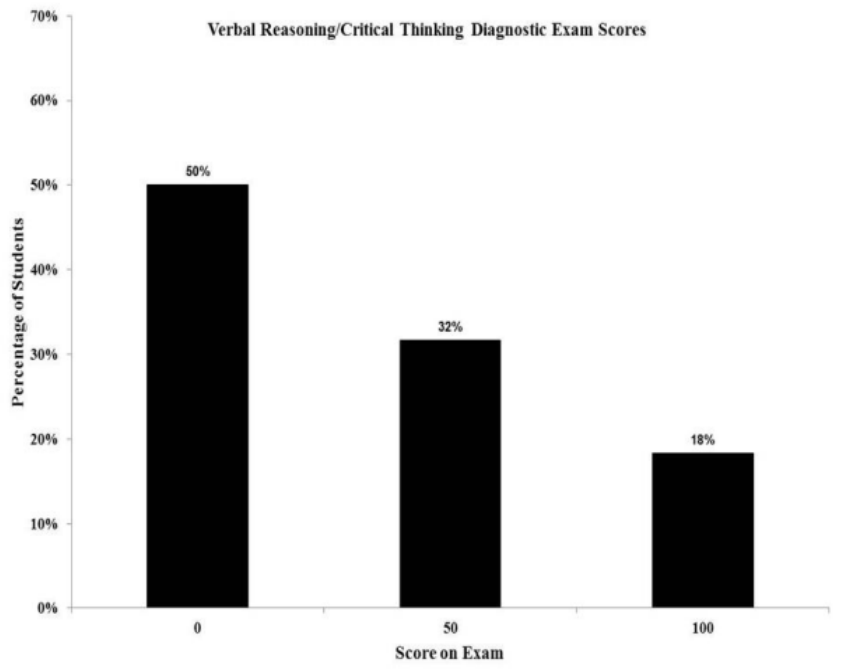

Figure 5. Results of the verbal reasoning / critical thinking diagnostic exam (abstract reasoning) given to students at AAMU enrolled in General Chemistry 101 and 102.

- Thinks open-mindedly within alternative systems of thought, recognizing and assessing, as need be, their assumptions, implications, and practical consequences

- Communicates effectively with others in figuring out solutions to complex problems.

In summary, the attitudes and the foundational levels of the students from AAMU currently enrolled in General Chemistry 101 and 102 were shown. The reason for these studies was to determine the effect of attitude and their foundational levels in mathematics and verbal reasoning/critical thinking on their overall success in General Chemistry. A large percentage of 
students believe that attitude determines their overall success, however they lack self-confidence. In addition, they appeared college ready with respect to their mathematical skills, but they were lacking in vocabulary and verbal reasoning/critical thinking skills. Collectively, this information has allowed AAMU to assess the current curriculum and attempt to identify various pedagogical approaches to overall enhance the General Chemistry experience for our undergraduates, which would ultimately lead to an increased number of students successfully matriculating through and graduating from STEM disciplines.

\section{Acknowledgments}

The authors would like to thank the Chemistry Professors and students at Alabama Agricultural and Mechanical University who participated in this research. In addition, we would like to acknowledge Alabama Agricultural and Mechanical University Interdisciplinary Center for Health Sciences and Health Disparities with funding provided through the Evans-Allen Grant, administered by the College of Agricultural, Life and Natural Sciences.

\section{References}

ACT (2006) Developing the STEM Education Pipeline.

Alabama Agricultural and Mechanical University. www.aamu.edu. American Association of State Colleges and Universities (2005) Strengthening the Science and Mathematics for a Better America. Vol. 2, Number 11.

Bayer Corporation (2010) Planting the Seeds for a Diverse US STEM
Pipeline: A Compendium of Best Practiced K-12 STEM Education Programs.

Burton NW, C Welsh, I Kostin, and T VanEssen (2009) Toward a Definition of Verbal Reasoning in Higher Education. Educational Testing Services.

Cal State University General Chemistry Course Redesign Project.

Conley DT (2011) Redefining College Readiness. Educational Policy Improvement Center. Vol. 5.

Donovan WJ and ER Wheland (2009) Comparisons of Success and Retention in a General Chemistry Course Before and After the Adoption of a Mathematics Pre-requisite. Wiley Publishing 109 (7).

Drew DE (2011) STEM the Tide: Reforming Science, Technology, Engineering and Mathematics Education in America. John Hopkins University Press.

Lewis SE, JL Shaw, and JO Heitz (2009) Attitude Counts: Self-Concept and Success in General Chemistry. Journal of Chemical Education 86 (6): 744

National Science Foundation (2006) America's Pressing Challenge Building a Stronger Foundation: A Companion to Science and Engineering Indicator.

National Science Foundation (2010) Preparing the Next Generation of STEM Innovators: Identifying and Developing our Nation's Human Capital.

Paul R and L Elder (2008) The Miniature Guide to Critical Thinking Concepts and Tools: Foundation for Critical Thinking Press.

Pfeiffer JW (1993) Barriers to the Advance of Organizational Science: Paradigm Development as a Dependent Variable The Academy of Management Review 18 (4): 599-620.

President's Council of Advisors on Science and Technology (PCAST) (2012) Report to the President and Congress on the Fourth Assessment of the National Nanotechnology Iniative. 